TITLE:

\title{
Kinetics of hydrolysis and methyl esterification for biodiesel production in two-step supercritical methanol process
}

\author{
AUTHOR(S): \\ Minami, Eiji; Saka, Shiro
}

\section{CITATION:}

Minami, Eiji ...[et al]. Kinetics of hydrolysis and methyl esterification for biodiesel production in two-step supercritical methanol process. Fuel 2006, 85(17-18): 2479-2483

\section{ISSUE DATE:}

2006-12

URL:

http://hdl.handle.net/2433/250169

\section{RIGHT:}

(c) 2008. This manuscript version is made available under the CC-BY-NC-ND 4.0 license http://creativecommons.org/licenses/by-nc-nd/4.0/.; この論文は出版社版でありません 。引用の際には出版社版をご確認ご利用ください。; This is not the published version. Please cite only the published version. 
Title:

Kinetics of hydrolysis and methyl esterification for biodiesel production in two-step supercritical methanol process

Authors: Eiji Minami and Shiro Saka

Affiliation: Graduate School of Energy Science, Kyoto University, Japan

Address: Yoshida-honmachi, Sakyo-ku, Kyoto 606-8501, Japan

Tel/Fax: +81 (0)75 7534738

E-mail: saka@energy.kyoto-u.ac.jp

Corresponding author: Shiro Saka 


\section{ABSTRACT}

For high-quality biodiesel fuel production from oils/fats, the catalyst-free two-step supercritical

methanol process has been developed in a previous work, which consists of hydrolysis of triglycerides

to fatty acids in subcritical water and subsequent methyl esterification of fatty acids to their methyl

esters in supercritical methanol. In this paper, therefore, kinetics in hydrolysis and subsequent methyl

esterification was studied to elucidate reaction mechanism. As a result, fatty acid was found to act as acid catalyst, and simple mathematical models were proposed in which regression curves can fit well with experimental results. Fatty acid was, thus, concluded to play an important role in the two-step supercritical methanol process.

\section{KEYWORDS}

Biodiesel, Supercritical methanol, Subcritical water 


\section{INTRODUCTION}

Biomass is considered as one of the key renewable energy resources for our society owing to its

high potential, economic feasibility and various social and environmental benefits. In addition, the depletion in petroleum reserves has worldwide stimulated the search for alternative sources for petroleum-based fuel, including diesel fuels. Because of these reasons, the use of biodiesel (fatty acid methyl esters; FAME) has been started worldwide.

Biodiesel fuel can be produced from oils/fats through transesterification of triglycerides (TG) with methanol. At present, most of the methods in transesterification use alkali catalysts [1]. In the alkali-catalyzed method, however, free fatty acids (FFA) react with a catalyst producing undesirable saponified products. Therefore, this process needs sophisticated purification steps for removal of the saponified products as well as catalyst, thus resulting in the lower yield in FAME. The acid-catalyzed method is, however, tolerant for the presence of FFA due to its simultaneous methyl esterification to FAME, but requires longer reaction time [2]. Although a pretreatment of FFA by acid catalyst followed by the alkali-catalyzed process has been developed to overcome such a disadvantage [3, 4], it would be essentially solved if a non-catalytic biodiesel production process is developed.

Our research group has, therefore, studied catalyst-free processes employing supercritical methanol (critical temperature $T_{\mathrm{c}}=239^{\circ} \mathrm{C}$, critical pressure $P_{\mathrm{c}}=8.09 \mathrm{MPa}$ ); one-step supercritical methanol process (Saka method) [5-7] and two-step supercritical methanol process (Saka-Dadan 
method) [8]. In the former process, transesterification reaction of TG proceeds without any catalyst due to high ionic product of methanol in supercritical state [5, 6]. In addition, FFA in oil/fat feedstocks can be simultaneously esterified to FAME in supercritical methanol [7], thus resulting in a higher yield of FAME, compared with the conventional alkali-catalyzed method. However, the reaction condition is drastic to be $350^{\circ} \mathrm{C}$ and $20 \sim 50 \mathrm{MPa}$ in the one-step process to enhance solvation effect in supercritical methanol.

The latter process, on the other hand, involves hydrolysis of TG to fatty acids (FA) in subcritical water and subsequent methyl esterification of FA together with FFA originally existed to FAME in supercritical methanol without any catalyst. This process can allow more moderate reaction conditions $\left(270^{\circ} \mathrm{C} / 7 \sim 20 \mathrm{MPa}\right)$ than those of the one-step process [8]. In the two-step method, furthermore, backward reaction of glycerol with methyl esters can be suppressed because glycerol is removed away prior to methyl esterification. Thus, high-quality biodiesel fuel can be produced, which has low total glycerol content, compared with the one-step method [8].

In this paper, therefore, a kinetic study was made for hydrolysis and subsequent esterification reactions to elucidate a mechanism for such mild reaction conditions in the two-step supercritical methanol process. 


\section{EXPERIMENTAL METHODS}

Figure 1 shows a laboratory-scale plant for the two-step supercritical methanol process developed in our laboratory. In this system, TG in oils/fats is firstly treated in subcritical water for hydrolysis reaction to produce FA. After hydrolysis, the reaction mixture is separated into oil phase and water phase in a phase separator. The oil phase (upper portion) consists mainly of FA, while the water phase (lower portion) contains glycerol. The separated oil phase is then mixed with methanol and treated at supercritical condition to produce methyl esters thorough esterification. After removing methanol and water, FAME can be obtained as biodiesel. Tubular reactors for hydrolysis and esterification are made of Hastelloy C-276 to prevent corrosions caused by supercritical fluid. The flow capacity of this system is up to $600 \mathrm{~mL} / \mathrm{hr}$ on oils/fats feedstock basis.

In this study, hydrolysis of TG and methyl esterification of FA were independently carried out using refined rapeseed oil and oleic acid, respectively. High-performance liquid chromatography (HPLC)-grade water and methanol were used as a solvent. These chemicals and solvents were purchased from Nacalai Tesque, Inc., Japan.

The treatments were conducted under the temperature between $250^{\circ} \mathrm{C}$ and $320^{\circ} \mathrm{C}$ with a constant pressure of $10 \mathrm{MPa}$ or $20 \mathrm{MPa}$. The reaction time $t$ (sec) was estimated by dividing the tubular volume $V(\mathrm{~mL})$ in the reactors by volumetric flow rate of reactants at designated reaction conditions as in the following equation: 


$$
t=\frac{V}{F_{S} \frac{\rho_{S}}{\rho_{S}{ }^{\prime}}+F_{O} \frac{\rho_{O}}{\rho_{O}{ }^{\prime}}}
$$

where $F_{\mathrm{s}}, \rho_{\mathrm{s}}$ and $\rho_{\mathrm{s}}$ ' are setting flow rate $(\mathrm{mL} / \mathrm{sec})$, specific densities $(\mathrm{g} / \mathrm{mL})$ at normal condition and reaction condition for solvent, respectively, while subscript "o" means those for oil. As the value of $\rho_{\mathrm{s}}$ ', a reference data by Goodwin [9] was used, while $\rho_{\mathrm{o}}$ ' was assumed to be equal to $\rho_{\mathrm{o}}$ at any reaction conditions.

After hydrolysis of TG in subcritical water, reaction mixture was evacuated under reduced pressure at $70^{\circ} \mathrm{C}$ for 20 min to remove water. Remaining portion was then separated into oil phase and glycerol by decantation. Obtained oil phase, which consists of FA as a major component as well as unreacted TG and intermediate compounds, diglycerides (DG) and monoglycerides (MG), was analyzed by HPLC chromatography carried out with a Shimadzu LC-10A system under the following conditions: i) column, Asahipak GF310-HQ; flow rate, $1.0 \mathrm{~mL} / \mathrm{min}$; eluent, acetone; detector, refractive index detector (RID); temperature, $40^{\circ} \mathrm{C}$ and ii) column, STR ODS-II; flow rate, $1.0 \mathrm{~mL} / \mathrm{min}$; eluent, methanol; detector, RID; temperature, $40^{\circ} \mathrm{C}$. Although rapeseed oil consists of various fatty acids, the major one is oleic acid constituting about $60 \%$ of all. Therefore, calibration curves for the quantitative determination of TG, DG, MG and FA were made using triolein, 1,3-diolein, 1-monoolein, which were purchased from Aldrich-Sigma, Japan, and oleic acid, respectively.

For methyl esterification of FA, a similar experimental procedure was employed as described above. In addition, rapeseed oil was also transesterified by one-step supercritical methanol process to compare reaction behaviors between two-step process (hydrolysis followed by methyl esterification) 
and one-step process (transesterification).

\section{RESULTS AND DISCUSSION}

\section{Hydrolysis of triglycerides in subcritical water}

Hydrolysis of oils/fats consists of three stepwise reactions: one molecule of TG is hydrolyzed to one molecule of DG to produce one molecule of FA, and DG is repeatedly hydrolyzed to MG which is further hydrolyzed to glycerol, producing three molecules of FA in total. As a backward reaction, however, glycerol reacts with FA to reverse to MG. As in a similar manner, DG and MG also return to TG and DG, respectively, consuming one molecule of FA. In subcritical water, this hydrolysis reaction with its backward reaction occurs without any catalyst [8].

Figure 2 shows the yield of FA obtained from rapeseed oil in subcritical water at various conditions. Although a higher temperature realized a higher rate of FA formation, the hydrolysis reaction always reached equilibrium at around $90 \mathrm{wt} \%$ in yield of FA when the volumetric ratio of water to rapeseed oil was $1 / 1$. This incomplete result might be due to the backward reaction mentioned above. Under the conditions of $270^{\circ} \mathrm{C}$ and $20 \mathrm{MPa}$, the yield of FA reached $90 \mathrm{wt} \%$ after the subcritical water treatment for $60 \mathrm{~min}$. 
With regard to time course of the yield, the yield of FA as a result of hydrolysis is very slowly increased in early stage of the reaction, especially at the lower temperature applied at $250^{\circ} \mathrm{C}$ and $270^{\circ} \mathrm{C}$. The rate of FA formation, then, gradually became higher when the treatment was prolonged, and finally reached plateau. This phenomenon suggests that FA produced by hydrolysis would act as acid catalyst in subcritical water.

Therefore, the autocatalytic reaction for hydrolysis can be proposed as shown in Figure 3. In this process, FA is dissociated to eliminate a proton, which causes the protonating carbonyl oxygen of TG $\left(\mathrm{TG}^{+}\right)$, thus allowing carbonyl carbon to receive nucleophilic attack by water. By this way, hydrolysis reaction of TG is promoted. The same reaction is repeatedly taken for DG and MG.

Assuming that the hydrolysis reactions of TG, DG and MG proceed through such autocatalytic mechanism by FA, reaction equations can be described as follows:

$$
\begin{gathered}
\frac{d C_{T G}}{d t}=\left(-k_{T G} C_{T G} C_{W}+k_{T G}{ }^{\prime} C_{D G} C_{F A}\right) \times C_{F A} \\
\frac{d C_{D G}}{d t}=\left(-k_{D G} C_{D G} C_{W}+k_{D G}{ }^{\prime} C_{M G} C_{F A}+k_{T G} C_{T G} C_{W}-k_{T G}{ }^{\prime} C_{D G} C_{F A}\right) \times C_{F A} \\
\frac{d C_{M G}}{d t}=\left(-k_{M G} C_{M G} C_{W}+k_{M G}{ }^{\prime} C_{G} C_{F A}+k_{D G} C_{D G} C_{W}-k_{D G}{ }^{\prime} C_{M G} C_{F A}\right) \times C_{F A} \\
\left(C_{F A}(t=0) \neq 0\right)
\end{gathered}
$$

where $C_{\mathrm{TG}}, C_{\mathrm{DG}}, C_{\mathrm{MG}}, C_{\mathrm{G}}, C_{\mathrm{FA}}$ and $C_{\mathrm{W}}$ refer to the concentrations of TG, DG, MG, glycerol, FA and water $\left(\mathrm{mol} / \mathrm{m}^{3}\right)$ in the reaction system, respectively. In each equation, the formula in parentheses depicts typical second-order-reaction, while the factor $C_{\mathrm{FA}}$ describes the effect of autocatalytic reaction by FA. 
Generally, the rate constants for TG, DG and MG are different from each other. In the case of transesterification, actually, Diasakou et al. reported that the value of $K_{\mathrm{MG}}$ was slightly lower than those of $K_{\mathrm{TG}}$ and $K_{\mathrm{DG}}$ [10]. In this study, however, rate constant for TG was simply assumed to be equal to those for DG and MG, because this study was focused to reveal the effect of FA on autocatalytic reaction. Based on this assumption, the rate of FA formation can be described as follows:

$$
\begin{gathered}
\frac{d C_{F A}}{d t}=\left(k C_{O} C_{W}-k^{\prime} C_{O}{ }^{\prime} C_{F A}\right) \times C_{F A} \\
\left(C_{O}=C_{T G}+C_{D G}+C_{M G}, C_{O}{ }^{\prime}=C_{D G}+C_{M G}+C_{G}\right)
\end{gathered}
$$

By applying the equation (5), time course of FA formation was described as theoretical curves by solid line, while the experimental results are plotted for rapeseed oil itself (FA 0wt\%) and FA-added rapeseed oil (FA 10wt\%) in Figure 4. It is quite apparent that the theoretical lines are fitted very well with the experimental results for both cases. As a result, when $10 \mathrm{wt} \%$ of oleic acid was added in rapeseed oil before the treatment, hydrolysis reaction reached equilibrium within only $40 \mathrm{~min}$, while in case of neat rapeseed oil, it took about 60min. In the former case, furthermore, an eventual yield of FA was slightly higher than that in the latter case.

Based on these lines of evidence, it was concluded that FA has an important role as acid catalyst in hydrolysis reaction of oils/fats in subcritical water. 


\section{Methyl esterification of fatty acids in supercritical methanol}

Methyl esterification of FA is a major reaction to produce FAME in the two-step supercritical

methanol process, whereas transesterification of TG is a major one in the conventional alkali- and acid-catalyzed methods. This esterification reaction is, therefore, an important step for high-quality biodiesel fuel production.

Figure 5 shows typical changes in the yield of FAME as oleic acid is treated in supercritical methanol at various conditions. In a similar manner to hydrolysis reaction, a higher temperature resulted in a faster rate of FAME formation. In addition, the yield of FAME tended to increase quickly in the early stage of the reaction, whereas the rate of FAME formation became slow when the reaction proceeded. Therefore, the reaction hardly reached equilibrium even after the treatment over $40 \mathrm{~min}$. It seems apparent that the rate of FAME formation is nearly connected with concentration of FA in the reaction system.

On the other hand, Figure 6 shows the effect of volumetric ratio of methanol to FA on methyl esterification reaction in supercritical methanol. As unexpectedly, the higher yield of FAME was achieved when the lesser amount of methanol was added to the reaction. For example, about $94 \mathrm{wt} \%$ of FAME could be obtained with a volumetric ratio of $0.9 / 1$ (methanol/FA), while only $80 \mathrm{wt} \%$ in case of $5.4 / 1$ in its ratio as treated at $270^{\circ} \mathrm{C}$ and $20 \mathrm{MPa}$ for $30 \mathrm{~min}$. 
Generally speaking in supercritical fluid science, an excessive amount of methanol should be added to suppress the backward reaction of FAME to FA. However, the result was not the case. This is because FA acts as acid catalyst so that the higher FA concentration as a result of a small amount of methanol used in the reaction system can enhance the methyl esterification reaction.

As in hydrolysis reaction, therefore, the autocatalytic mechanism by FA (Figure 7) was applied for methyl esterification reaction as in the following equation:

$$
\frac{d C_{F A M E}}{d t}=\left(k C_{F A} C_{M}-k^{\prime} C_{F A M E} C_{W}\right) \times C_{F A}
$$

where $C_{\mathrm{FAME}}, C_{\mathrm{M}}, C_{\mathrm{FA}}$ and $C_{\mathrm{W}}$ refer to the concentrations of FAME, methanol, FA and water $\left(\mathrm{mol} / \mathrm{m}^{3}\right)$, respectively.

Based on the equation (6), the obtained theoretical curves fitted well with experimental results as represented by solid lines in Figure 6. Dependence of the volumetric ratio of methanol on FAME yield could be, thus, explained by the autocatalytic mechanism of FA. Similarly, time courses of the FAME yield in Figure 5 were also explained by the fact that the faster conversion of FA to FAME should be originated from the higher concentration of FA in the early stage of the reaction.

\section{Comparison between one-step and two-step processes}

On transesterification of TG in the one-step supercritical methanol process, the yield of FAME is shown in Figure 8. In this case, severe reaction conditions over $320^{\circ} \mathrm{C}$ were required for efficient 
conversion to FAME, compared with the two-step process. In addition, it is obvious that the time course of FAME yield follows a typical pseudo-first-order reaction in Figure 8. It indicates that the transesterification of oils/fats is proceeded only by methanolysis ability of supercritical methanol itself, since there is no FA in the reaction system.

\section{CONCLUSION}

In this study, a kinetic study was made on hydrolysis of oils/fats in subcritical water and the following methyl esterification of FA in supercritical methanol, respectively, to optimize reaction conditions for the two-step supercritical methanol process.

For the hydrolysis reaction, the rate of FA formation was increased with the amount of FA produced, though it was very slow in the early stage of the reaction. This phenomenon can be explained by assuming that FA acts as acid catalyst. For the esterification reaction, similarly, the reaction was found to proceed by the autocatalytic mechanism due to dissociation of FA itself in supercritical methanol. In this way, it was found that the produced FA plays an important role in the non-catalytic two-step supercritical methanol process.

These findings in this study will contribute to development of more efficient method for the two-step supercritical methanol process. In case of the hydrolysis reaction, for example, the addition of 
FA to oil/fat feedstocks before subcritical water treatment is expected to realize more efficient hydrolysis due to the acidic character of FA. As a similar purpose, we can feed a part of produced FA back to the inlet of the tubular reactor. For the methyl esterification reaction, on the other hand, a lesser amount of methanol is more preferable to get a faster rate of FAME formation, thus achieving the higher energy efficiency for biodiesel fuel production.

\section{ACKNOWLEDGEMENTS}

This work has been done in the Kyoto University 21 COE program "Establishment of COE on Sustainable-Energy System”, and in part in NEDO "High Efficiency Bioenergy Conversion Projects”, for all of which the authors are highly acknowledged. 


\section{REFERENCES}

[1] Freedman B, Pryde EH, Mounts TL. Variables affecting the yields of fatty esters from transesterified vegetable oils. JAOCS 1984; 61: 1638-43.

[2] Lotero E, Liu Y, Lopez DE, Suwannakarn K, Bruce DA, Goodwin JG. Synthesis of biodiesel via acid catalysis. Ind Eng Chem Res 2005; 44: 5353-63.

[3] Boocock DGB. Biodiesel fuel from waste fats and oils: A process for converting fatty acids and triglycerides. In: Saka S, Kawamoto H, Miyafuji H, editors. Proc Kyoto Univ Int Symp on Post Petrofuels in the 21st Century, Tokyo: Industrial Publishing \& Consulting Inc; 2002. p. 171-177.

[4] Ramadhas AS, Jayaraj S, Muraleedharan C. Biodiesel production from high FFA rubber seed oil. Fuel 2005; 84: 335-40.

[5] Saka S, Kusdiana D. Biodiesel fuel from rapeseed oil as prepared in supercritical methanol. Fuel 2001; 80: 225-31.

[6] Kusdiana D, Saka S. Kinetics of transesterification in rapeseed oil to biodiesel fuel as treated in supercritical methanol. Fuel 2001; 80: 693-98.

[7] Kusdiana D, Saka S. Methyl esterification of free fatty acids of rapeseed oil as treated in supercritical methanol. J Chem Eng Jpn 2001; 34: 383-87.

[8] Kusdiana D, Saka S. Two-step preparation for catalyst-free biodiesel fuel production: Hydrolysis and methyl esterification. Appl Biochem Biotechnol 2004; 115: 781-92. 
[9] Goodwin RD. Methanol thermodynamic properties from 176 to $673 \mathrm{~K}$ at pressures to 700 bar. $\mathrm{J}$ Phys Chem Ref Data 1987; 16: 799-892.

[10] Diasakou M, Louloudi A, Papayannakos N. Kinetics of the non-catalytic transesterification of soybean oil. Fuel 1998; 77: 1297-1302. 


\section{LIST OF FIGURES}

Figure 1: A laboratory-scale plant of the two-step supercritical methanol process for biodiesel production.

Figure 2: Hydrolysis of rapeseed oil (TG) to fatty acids (FA) in subcritical water at 20MPa (Water/TG $=1 / 1(\mathrm{v} / \mathrm{v}))$.

Figure 3: Autocatalytic reaction by FA for hydrolysis of TG in subcritical water. $\left(\mathrm{H}^{+}\right.$, proton; $\mathrm{TG}^{+}$, protonated TG; FA, protonated FA; a similar route can be given for hydrolysis of DG and MG)

Figure 4: Hydrolysis of rapeseed oil (FA 0 wt\%) and FA-added rapeseed oil (FA $10 \mathrm{wt} \%$ ) in subcritical water at $270^{\circ} \mathrm{C}$ and $10 \mathrm{MPa}($ Water/oil $=1 / 1(\mathrm{v} / \mathrm{v}))$.

Figure 5: Methyl esterification of oleic acid to its methyl ester in supercritical methanol at $20 \mathrm{MPa}$ $(\mathrm{MeOH} / \mathrm{FA}=1.8 / 1(\mathrm{v} / \mathrm{v}))$

Figure 6: Methyl esterification of oleic acid to its methyl ester in supercritical methanol at $270^{\circ} \mathrm{C}$ and $20 \mathrm{MPa}$ with various volumetric ratios of $\mathrm{MeOH} / \mathrm{FA}$. 
Figure 7: Autocatalytic reaction by FA for methyl esterification of FA in supercritical methanol. $\left(\mathrm{H}^{+}\right.$, proton; $\mathrm{FA}^{+}$, protonated FA; $\mathrm{FAME}^{+}$, protonated FAME)

Figure 8: Transesterification of rapeseed oil (TG) to FAME in supercritical methanol at $20 \mathrm{MPa}$ $(\mathrm{MeOH} / \mathrm{TG}=1.8 / 1(\mathrm{v} / \mathrm{v}))$. 


\section{LIST OF FIGURES}

Figure 1: A laboratory-scale plant of the two-step supercritical methanol process for biodiesel production.

Figure 2: Hydrolysis of rapeseed oil (TG) to fatty acids (FA) in subcritical water at 20MPa (Water/TG $=1 / 1(\mathrm{v} / \mathrm{v}))$.

Figure 3: Autocatalytic reaction by FA for hydrolysis of TG in subcritical water. $\left(\mathrm{H}^{+}\right.$, proton; $\mathrm{TG}^{+}$, protonated TG; FA+, protonated FA; a similar route can be given for hydrolysis of DG and MG)

Figure 4: Hydrolysis of rapeseed oil (FA 0 wt\%) and FA-added rapeseed oil (FA $10 \mathrm{wt} \%$ ) in subcritical water at $270^{\circ} \mathrm{C}$ and $10 \mathrm{MPa}($ Water/oil $=1 / 1(\mathrm{v} / \mathrm{v}))$.

Figure 5: Methyl esterification of oleic acid to its methyl ester in supercritical methanol at $20 \mathrm{MPa}$ $(\mathrm{MeOH} / \mathrm{FA}=1.8 / 1(\mathrm{v} / \mathrm{v}))$

Figure 6: Methyl esterification of oleic acid to its methyl ester in supercritical methanol at $270^{\circ} \mathrm{C}$ and $20 \mathrm{MPa}$ with various volumetric ratios of $\mathrm{MeOH} / \mathrm{FA}$. 
Figure 7: Autocatalytic reaction by FA for methyl esterification of FA in supercritical methanol. $\left(\mathrm{H}^{+}\right.$, proton; $\mathrm{FA}^{+}$, protonated FA; $\mathrm{FAME}^{+}$, protonated FAME)

Figure 8: Transesterification of rapeseed oil (TG) to FAME in supercritical methanol at $20 \mathrm{MPa}$ $(\mathrm{MeOH} / \mathrm{TG}=1.8 / 1(\mathrm{v} / \mathrm{v}))$. 


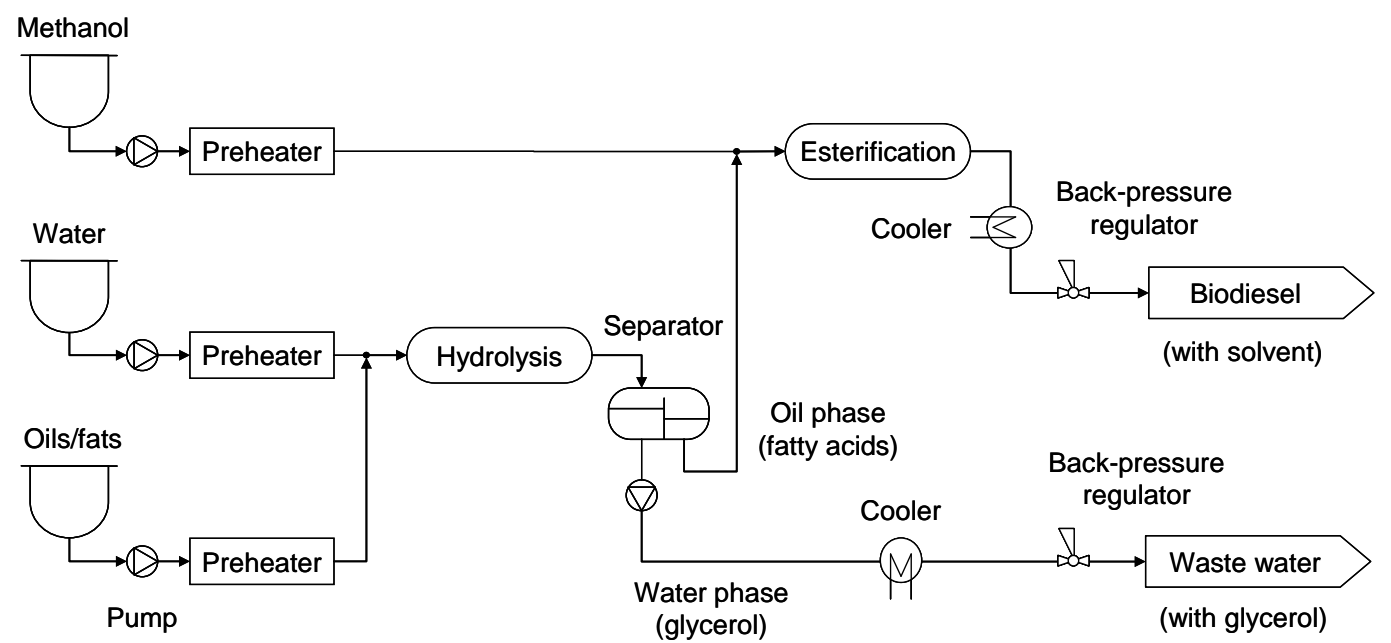

Fuel

Minami \& Saka

Figure 1 


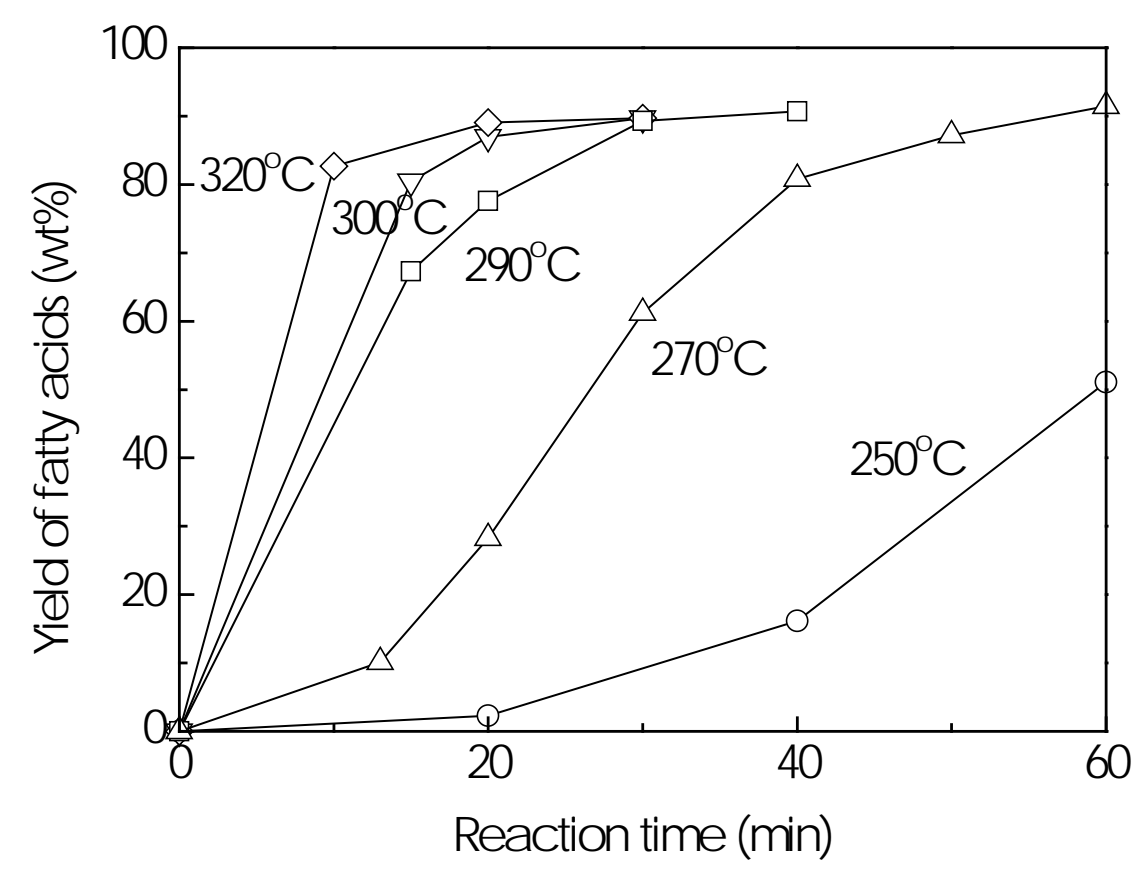

Fuel

Minami \& Saka

Figure 2 


\begin{tabular}{|c|c|c|c|c|c|c|c|}
\hline \multirow{2}{*}{\multicolumn{3}{|c|}{$A$}} & \multirow{2}{*}{$\longrightarrow$} & & \multirow[b]{2}{*}{+} & \multirow[b]{2}{*}{$\mathrm{H}^{+}$} & \multirow[b]{2}{*}{ (dissociation of FA) } \\
\hline & & & & $\mathrm{FA}^{-}$ & & & \\
\hline TG & + & $\mathrm{H}^{+}$ & $\longleftrightarrow$ & $\mathrm{TG}^{+}$ & & & (protonation to $\mathrm{TC}$ \\
\hline $\mathrm{TG}^{+}$ & + & $\mathrm{H}_{2} \mathrm{O}$ & & DG & + & $\mathrm{FA}^{+}$ & (hydrolysis of TG) \\
\hline & & $\mathrm{FA}^{+}$ & $\rightleftarrows$ & FA & + & $\mathrm{H}^{+}$ & (deprotonation) \\
\hline
\end{tabular}

Fuel

Minami \& Saka

Figure 3 


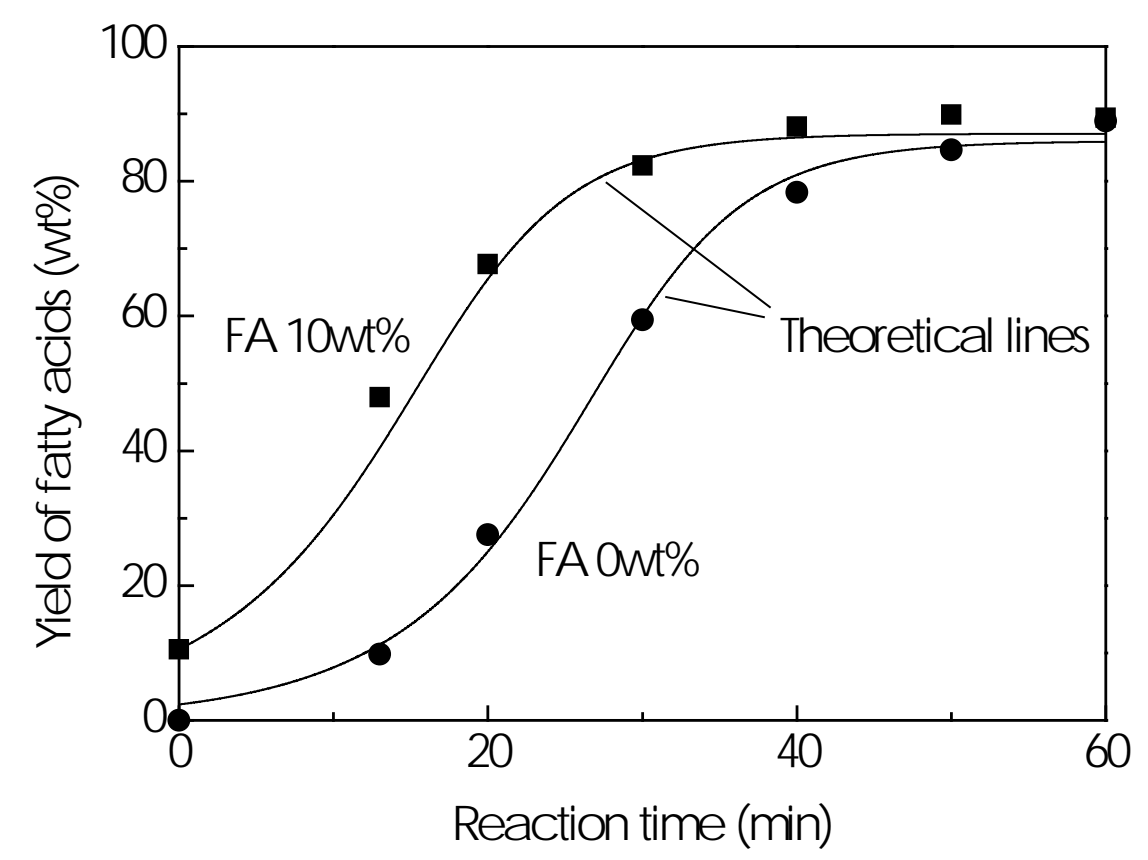

Fuel

Minami \& Saka

Figure 4 


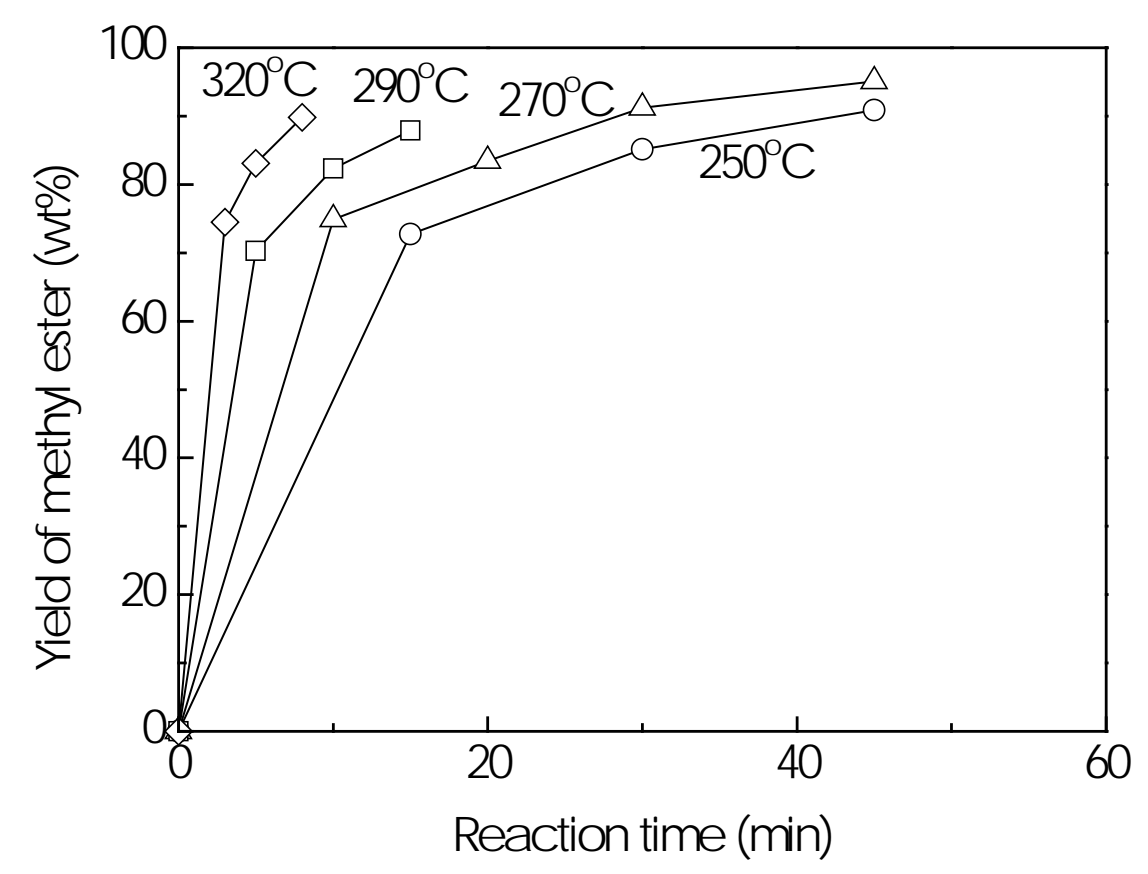

Fuel

Minami \& Saka

Figure 5 


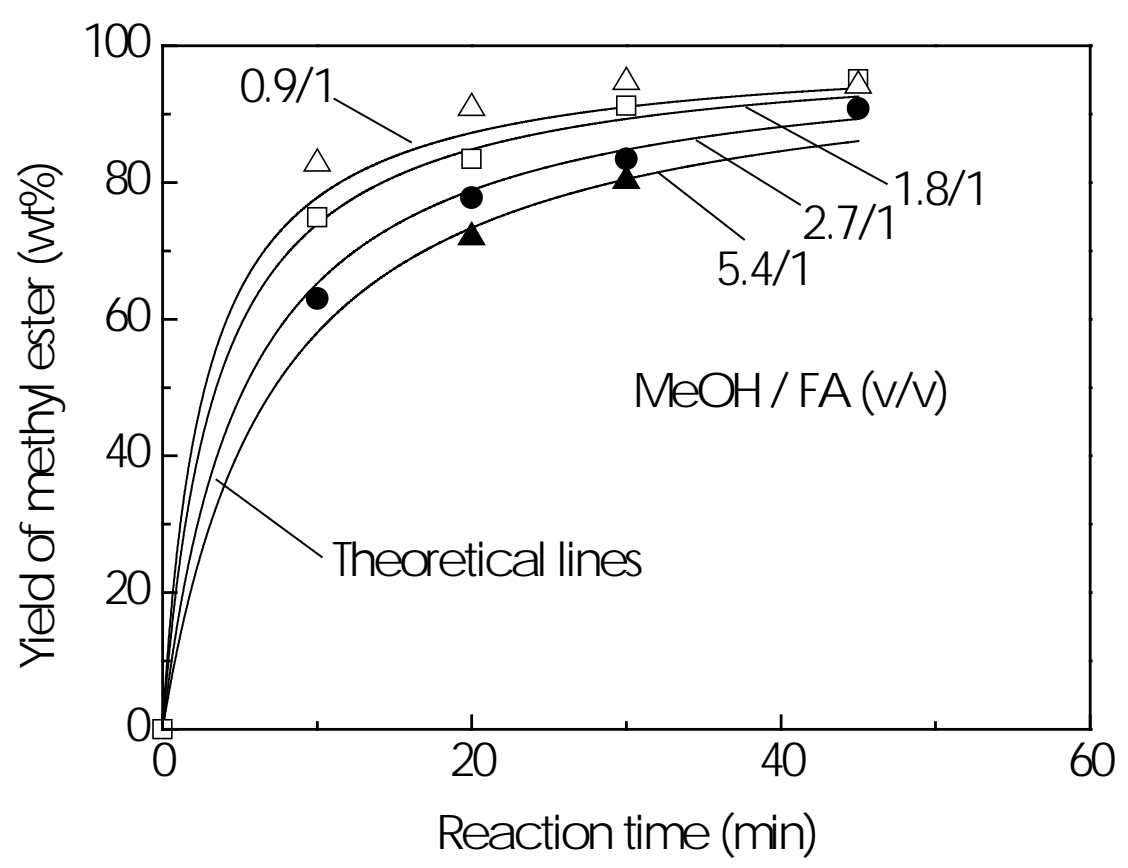

Fuel

Minami \& Saka

Figure 6 


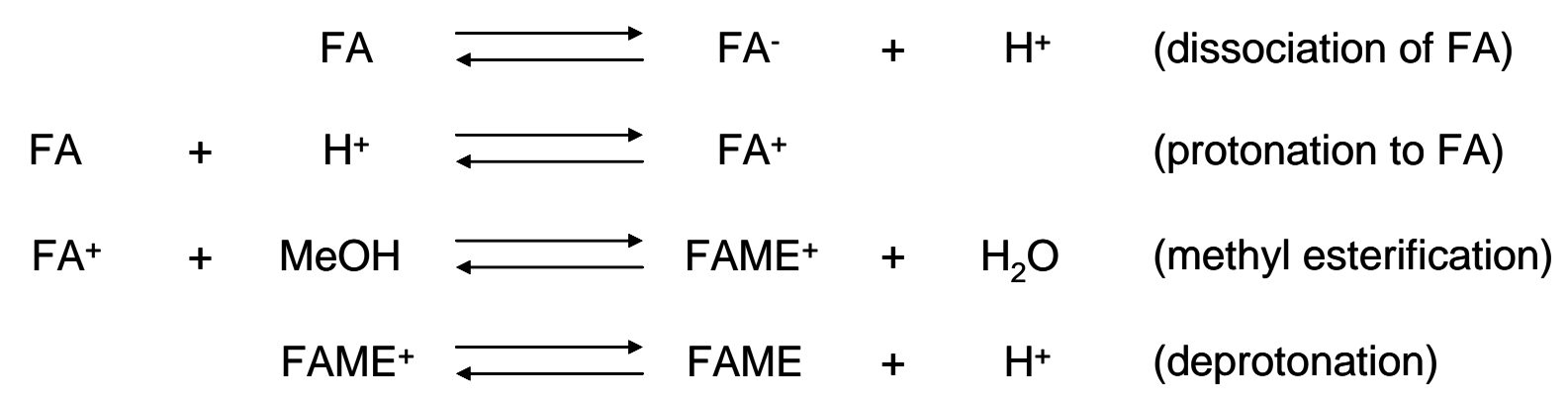

Fuel

Minami \& Saka

Figure 7 


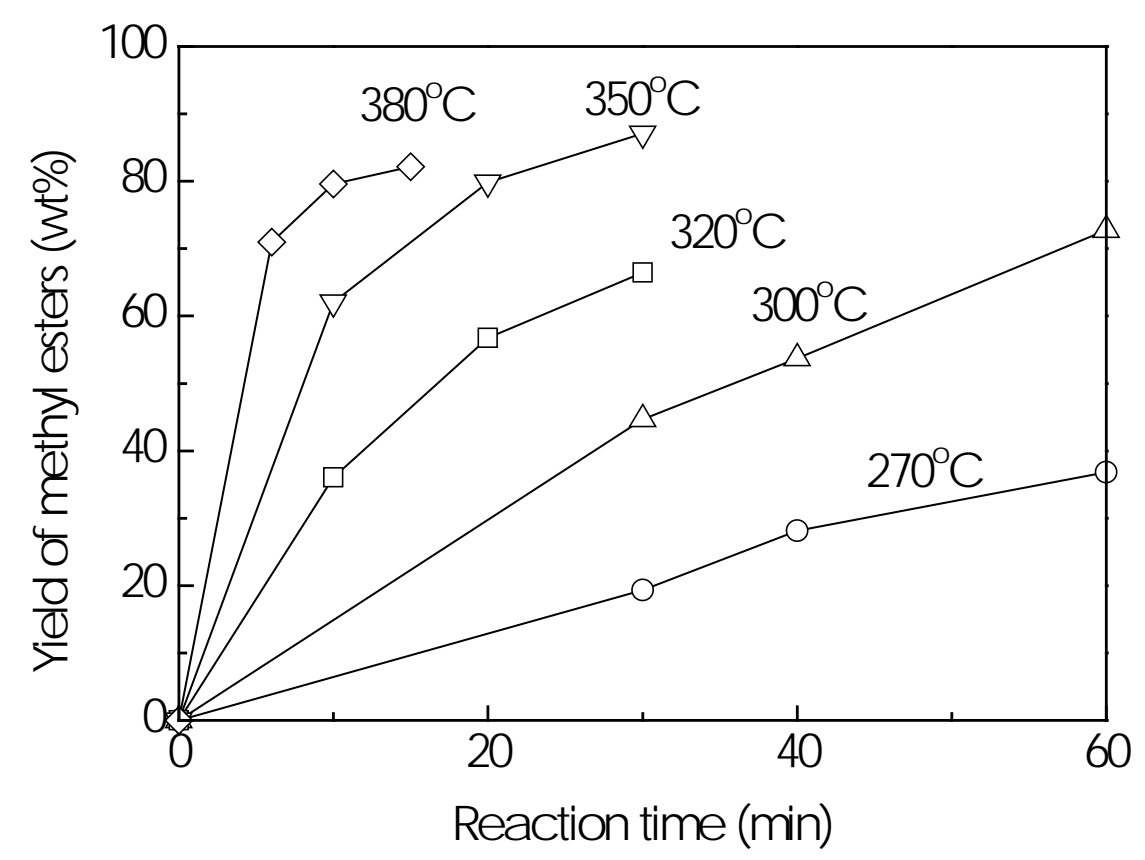

Fuel

Minami \& Saka

Figure 8 